\title{
Pengaruh Penyuluhan Kesehatan Reproduksi Remaja Terhadap Pengetahuan Remaja Putri Tentang Pencegahan Kejadian Leukorea Di SMKN 3 Banjarmasin
}

\author{
St. Hateriah1, Rizqy Amelia1, Nur Ilma Ifadah1 \\ 1AKBID Sari Mulia Banjarmasin \\ *correspondence author: Handphone:081348501160, E-mail: siti.hateriah@yahoo.com \\ DOI: https://doi.org/10.33859/dksm.v10i1.449
}

\begin{abstract}
ABSTRAK
Latar Belakang: Hasil penelitian tahun 2012, 70\% wanita pernah mengalami keputihan, tahun 2013 bulan Januari hingga Agustus hampir 55\% wanita pernah mengalami keputihan.

Tujuan: Dari hasil studi pendahuluan didapatkan 6 dari 15 siswi tidak mengetahui perbedaan keputihan fisiologis dan patologis serta 7 dari 15 siswi tidak mengetahui cara pencegahan keputihan abnormal.

Metode: Metode yang digunakan dalam penelitian ini adalah Pre Eksperimental dengan rancangan penelitian One Group Pretest-Postest. Sampel yang digunakan sebanyak 30 orang (sampel minimal). Data didapatkan dari kuesioner pre test dan post test. Data dianalisis menggunakan uji Marginal Homogeinity.

Hasil: Berdasarkan 30 orang responden terdapat 53,3\% berpengetahuan baik saat pre test dan 100\% berpengetahuan baik pada saat post test. Hasil uji marginal homegeinity yaitu $p 0.000 \leq a 0.05$.

Simpulan: Ada pengaruh penyuluhan kesehatan reproduksi terhadap pengetahuan remaja putri tentang leukorea.

Kata Kunci : Kesehatan Reproduksi, Leukorea, Pengetahuan dan Remaja Putri.
\end{abstract}

The effect of youth reproductive health extension Against youth knowledge of the daughter about Prevention of leukorea events At smk 3 banjarmasin

\section{Abstract}

Objective: The results of the study in 2012, $70 \%$ of women had experienced vaginal discharge, in 2013 from January to August nearly 55\% of women had experienced vaginal discharge.

Aim: From the results of the preliminary study, 6 out of 15 female students did not know the difference in physiological and pathological vaginal discharge and 7 out of 15 female students did not know how to prevent abnormal vaginal discharge.

Method: The method used in this study was Pre Experimental with the Pretest-Posttest One Group research design. The sample used was 30 people (minimum sample). Data obtained from the questionnaire pre test and post test. Data were analyzed using the Marginal Homogeinity test.

Results: Based on 30 respondents there were 53.3\% knowledgeable both at the pre test and 100\% knowledgeable at the time of the post test. The results of the marginal homegeinity test are $p 0,000 \leq$ a 0.05 .

Conslusion: There is the influence of reproductive health counseling on the knowledge of young women about leukorrhea.

Keywords : Reproductive Health, Leukorea, Knowledge and Young Women. 


\section{Pendahuluan}

Kesehatan reproduksi merupakan

kesehatan utama di masa remaja, karena hal ini merefleksikan kesehatan masa kanak - kanak.

Masa remaja menunjukan suatu transisi perjalanan hidup dari masa kanak - kanak yang terbebas dari beban tanggung jawab sampai pada masa dewasa dengan berbagai tanggung jawab (Manuaba et al, 2009). Kesehatan Reproduksi remaja adalah suatu kondisi atau keadaan sehat secara menyeluruh baik kesejahteraan fisik, mental dan sosial yang utuh dalam segala hal yang berkaitan dengan fungsi, peran dan proses reproduksi yang dimiliki oleh remaja (Nugroho, 2012).

Masalah - masalah kesehatan reproduksi menunjukan minimnya pengetahuan akan kesehatan reproduksi. Pendidikan mengenai kesehatan reproduksi merupakan salah satu solusi pencegahan terhadap terjadinya hal tersebut. Penyuluhan oleh lembaga seperti BKKBN merupakan salah satu cara pendidikan kesehatan reproduksi. Penyuluhan lebih banyak dilaksanakan di tingkat Sekolah Menengah Atas (SMA) daripada Sekolah Menengah Pertama (SMP)

(Badan Kependudukan dan Keluarga

Berencana Nasional (BKKBN), 2012).

Salah satu masalah kesehatan reproduksi pada remaja yaitu masalah keputihan. Keputihan (flour albus, leukorhea, atau white discharge) merupakan gejala yang berupa cairan yang dikeluarkan dari alat-alat genital yang tidak berupa darah (Hutabarat, 2007). Pengeluaran cairan ini sebagai keadaan dari saluran kelamin wanita. Seluruh permukaan saluran kelamin wanita mempunyai kemampuan untuk mengeluarkan cairan berupa lendir jernih, tidak berwarna dan tidak berbau busuk (Putu, 2009).

Nurul, dkk. (2011). Di Indonesia sebanyak $75 \%$ wanita pernah mengalami Keputihan minimal satu kali dalam hidupnya dan $45 \%$ diantaranya bisa mengalami keputihan sebanyak dua kali atau lebih. Kasus keputihan di Indonesia semakin meningkat. Berdasarkan hasil penelitian menyebutkan bahwa tahun 2010, 52\% wanita di Indonesia mengalami keputihan, kemudian tahun 2011, 60\% wanita pernah mengalami keputihan, sedangkan tahun 
2012 hampir 70\% wanita di Indonesia pernah mengalami keputihan, dan pada tahun 2013 bulan januari hingga agustus hampir $55 \%$ wanita pernah mengalami keputihan (Octaviana,2012). Berdasarkan data yang di dapat dari Dinas Kesehatan Kota Banjarmasin tahun 2012 terdapat $107 \quad(1,07 \%)$ kasus keputihan.

Berdasarkan studi pendahuluan yang dilakukan pada tanggal 27 November 2017 di SMK Negeri 3 Banjarmasin melalui wawancara didapatkan 6 dari 15 siswi tidak mengetahui perbedaan keputihan fisiologis dan patologis serta 7 dari 15 siswi tidak mengetahui cara pencegahan keputihan abnormal.

Berdasarkan latar belakang diatas, maka perlu untuk dilakukan penelitian dengan judul "Pengaruh Penyuluhan Kesehatan Reproduksi Remaja terhadap Pengetahuan Remaja Putri tentang Pencegahan Kejadian Leukorea di SMKN 3 Banjarmasin”.

\section{Metode Penelitian}

Penelitian ini dilakukan di SMK N 3

Banjarmasin pada tanggal 7-10 Maret 2018. Metode yang digunakan dalam penelitian ini adalah Pre Eksperimental dengan rancangan penelitian One Group Pretest-Postest. Rancangan One Group Pretest-Postest merupakan rancangan penelitian yang tidak menggunakan kelompok kontrol (pembanding), tetapi sudah melakukan pengukuran pertama (pretest) yang memungkinkan peneliti dapat menguji perubahan yang terjadi setelah adanya eksperimen. Populasi dalam penelitian ini adalah seluruh siswi kelas X SMK Negeri 3 Banjarmasin yang berjumlah 361 orang.

Sampel dalam penelitian ini berjumlah 30 orang. Teknik pengambilan sampel adalah proportionate stratified random sampling. Teknik pengumpulan data yang digunakan pada penelitian ini adalah kuesioner pre-test dan post-test. Data dianalisis menggunakan uji Marginal Homogeinity. 


\section{Hasil Penelitian}

1. Karakteristik Responden

Tabel 1 Karakteristik responden berdasarkan umur di kelas $\mathrm{X}$ SMK Negeri 3 Banjarmasin

\begin{tabular}{rcc}
\hline Umur & Frekuensi & Persentase \\
\hline 15 tahun & 11 & $36,7 \%$ \\
16 tahun & 18 & $60 \%$ \\
17 tahun & 1 & $3,3 \%$ \\
\hline Jumlah & 30 & $100 \%$ \\
\hline
\end{tabular}

Berdasarkan karakteristik responden dapat diketahui paling banyak berumur 16 tahun $(60 \%)$ diikuti oleh umur 15 tahun $(36,7 \%)$ dan umur 17 tahun $(3,3 \%)$.

2. Analisis Univariat

Tabel 2 Pre Test Pengetahuan Remaja Putri tentang Pencegahan Kejadian Leukorea

\begin{tabular}{lcc}
\hline Kategori & Frekuensi & Persentase \\
\hline Kurang & 1 & $3.3 \%$ \\
Cukup & 13 & $43.3 \%$ \\
Baik & 16 & $53.3 \%$ \\
\hline Jumlah & 30 & $100 \%$ \\
\hline
\end{tabular}

Berdasarkan tabel 5 dapat diketahui

bahwa ada 16 siswi $(53.3 \%)$

berpengetahuan baik sebelum diberikan
Berdasarkan tabel 3 dapat

diketahui bahwa semua responden (100\%)

berpengetahuan baik setelah diberikan

penyuluhan.

3. Analisis Bivariat

\begin{tabular}{|c|c|c|c|}
\hline abel 4 Hasil & $\begin{array}{l}\text { analisis pen } \\
\text { reproduksi } \\
\text { remaja putr } \\
\text { leukorea. }\end{array}$ & $\begin{array}{l}\text { h penyul } \\
\text { aja terhad } \\
\text { itang penc }\end{array}$ & $\begin{array}{r}\text { kesehatar } \\
\text { engetahuar } \\
\text { an kejadiar }\end{array}$ \\
\hline Variabel & \multicolumn{3}{|c|}{ Std. } \\
\hline $\begin{array}{l}\text { Pre Test } \\
\text { Post Test }\end{array}$ & 2216.000 & 43.818 & 0.000 \\
\hline
\end{tabular}

Berdasarkan tabel 4 menunjukkan

bahwa nilai Pre Test dan Post Test mean

2216.000, nilai standar deviasi 43.818 dan

nilai $p 0.000 \leq a 0.05$, maka Ha diterima.

Hal ini menunjukkan bahwa penyuluhan

kesehatan reproduksi mempunyai

pengaruh yang signifikan terhadap

pengetahuan remaja putri tentang

pencegahan kejadian Leukorea. penyuluhan.

Tabel 3 Post Test Pengetahuan Remaja Putri tentang Pembahasan

\begin{tabular}{lcc}
\multicolumn{3}{c}{ Pencegahan Kejadian Leukorea } \\
\hline Kategori & Frekuensi & Persentase \\
\hline Kurang & 0 & $0 \%$ \\
Cukup & 0 & $0 \%$ \\
Baik & 30 & $100 \%$ \\
\hline Jumlah & 30 & $100 \%$ \\
\hline
\end{tabular}

1. Identifikasi Pengetahuan Remaja tentang Pencegahan Kejadian Leukorea Sebelum dilakukan Penyuluhan

Hasil Penelitian terhadap pengetahuan sebelum dilakukan 
penyuluhan sesuai tabel 4.5 hanya terdapat

16 orang reponden

berpengetahuan baik sebelum diberikan penyuluhan.

Remaja yang berpengetahuan baik terdapat lebih dari $50 \%$ sampel yaitu ada 16 orang (53.3\%). Hal ini cukup baik, karena sebelum diberikan penyuluhan tentang pencegahan kejadian leukorea, banyak remaja yang sudah memiliki modal pengetahuan awal tentang leukorea. Salah satu faktor yang menyebabkan banyaknya remaja dengan pengetahuan baik tentang leukorea yaitu dekatnya wilayah sekolah dengan puskesmas terminal, sehingga kadang puskesmas datang ke sekolah dan memberikan penyuluhan seputar kesehatan kepada remaja. Selain itu, pendidikan awal yang diberikan orang tua tentang merawat organ genitalia juga memberikan dampak positif bagi pengetahuan remaja.

Berdasarkan hasil penelitian, pernyataan nomor 2 mendapatkan nilai terendah pada saat pre test yaitu penyataan
"Menjaga kuku tetap bersih dan pendek bukan merupakan cara mencegah keputihan abnormal". Hal ini terjadi karena rendahnya pengetahuan remaja tentang keputihan dan faktor-faktor yang menyebabkan keputihan menjadi salah satu penyebabnya. Pada saat penelitian, peneliti melihat banyak kuku siswi yang membiarkan kukunya panjang. Sebagian wanita memang senang memanjangkan kuku agar terlihat lebih feminin dan mudah untuk dibentuk maupun dihias. Tapi jika tidak benar memeliharanya, kuku Panjang bisa menjadi sumber penyakit dan penyebab terjadinya gangguan kesehatan, salah satunya keputihan. Kuku yang panjang menjadi tempat bersarangnya kuman sedangkan tangan digunakan untuk mencebok atau membersihkan organ genitalia. Jika kuku yang panjang dibiarkan saat mencebok maka secara tidak langsung kuman yang bersarang di kuku itupun juga masuk ke organ genitalia. Sehingga hal itulah yang menyebabkan terjadinya keputihan. 
Menurut Notoadmojo (2012) selain menggunakan panca indera, individu memperoleh pengetahuan dari proses belajar, baik melalui pendidikan formal maupun informasl. Dalam proses belajar, rangsangan atau stimulus yang diterima oleh individu berupa informasi tentang inovasi, tertimbun dalam diri individu sampai yang bersangkutan memberikan respon atau (tanggapan) tentang inovasi tersebut, yaitu menerima atau menolak. Adanya rangsangan atau stimuli, kemudia timbul reaksi atau respon terhadap stimulus tersebut yang dinamakan proses belajar.

Hal ini sejalan dengan penelitian Ratna (2010), pengetahuan dan perawatan yang baik merupakan faktor penentu dalam memelihara kesehatan reproduksi. Salah satu terjadinya gejala kelainan atau penyakit pada organ reproduksi adalah keputihan yang dialami oleh sebagian besar wanita.

Pengetahuan adalah salah satu faktor predisposing terbentuknya perilaku pada remaja, yaitu faktor yang memotivasi.
Faktor ini berasal dari dalam diri seorang remaja yang menjadi alasan atau motivasi untuk melakukan suatu perilaku. Pentingnya remaja mengetahui tentang keputihan adalah agar wanita khususnya remaja mengetahui tentang keputihan, tanda dan gejala keputihan, penyebab, dan dapat membedakan antara keputihan fisiologis dan patologis sehingga wanita dapat mencegah, menangani dan segera melakukan pemeriksaan apabila terdapat tanda dan gejala keputihan yang tidak normal (Lestary, 2007).

2. Identifikasi Pengetahuan Remaja tentang Pencegahan Kejadian Leukorea Sesudah dilakukan Penyuluhan

Setelah dilakukan penyuluhan kepada para remaja di SMK Negeri 3 Banjarmasin, peneliti memberikan kuesioner post test dengan hasil sesuai tabel 4.6 didapatkan bahwa 30 orang (100\%) atau semua responden berpengetahuan baik setelah diberikan penyuluhan. 
Berdasarkan hasil penelitian, pernyataan nomor 2 mendapatkan nilai terendah pada saat pre test yaitu penyataan "Menjaga kuku tetap bersih dan pendek bukan merupakan cara mencegah keputihan abnormal". Namun, setelah diberikan penyuluhan terdapat kenaikan yang signifikan, pada pre test hanya 10 orang yang benar dalam menjawab pernyataannya, pada post test ada 17 orang orang yang benar. Hal ini menunjukkan bahwa penyuluhan dianggap efektif dalam menambah pengetahuan siswi tentang pencegahan kejadian leukorea. Pada saat post test nilai terendah diperoleh oleh pernyataan nomor 23 "Penyakit radang panggul (pelvic inflammatory disease) merupakan infeksi alat genital bagian atas wanita yang terjadi bukan karena akibat hubungan seksual”. SMK Negeri 3 Banjarmasin adalah SMK dengan program ekonomi, pariwisata dan Teknik, jauhnya informasi tentang kesehatan merupakan salah satu penyebab kurangnya pengetahuan remaja tentang penyakit.
Pada saat penyuluhan, peneliti sudah menjelaskan tentang anatomi organ genitalia luar dan dalam kepada siswi dengan menggunakan gambar pada power point. Peneliti juga telah menjelaskan letak munculnya penyakit di organ genitalia. Kemungkinan lain yaitu siswi kesulitan dalam memahami penjelasan peneliti karena para siswi tidak terbiasa menerima pelajaran tentang kesehatan, khususnya tentang anatomi tubuh. Hal ini membuat peneliti bingung, pada saat penyuluhan semua siswi. Nampak memahami dan merespon peneliti. Pada saat peneliti menawarkan apakah ada yang bertanya juga tidak ada yang bertanya, sehingga peneliti berpendapat semua siswi sudah paham, tapi pada saat post test masih ada yang salah dalam menjawab pernyataan nomor 23 dan pernyataan yang lain. Banyak hal yang dapat menjadi faktor penyebabnya. Kemungkinan besar, pada saat penyuluhan, remaja tersebut tidak memperhatikan apa yang disampaikan oleh peneliti. 
Telah terjadi peningkatan yang signifikan pada pengetahuan remaja setelah diberikan penyuluhan. Remaja putri di SMK Negeri 3 Banjarmasin sudah memiliki modal awal pengetahuan tentang Leukorea yang didapat dari penyuluhan dari puskesmas, pendidikan awal dari orang tua serta dari rasa ingin tahu remaja itu sendiri dengan cara membrowsing tentang leukorea atau keputihan di internet.

Hal ini sejalan dengan pendapat Muninjaya (2011) bahwa penyuluhan kesehatan akan membawa pada perubahan sikap dan perilaku dari individu, keluarga maupun masyarakat dengan menanamkan prinsip-prinsip sehat dalam kesehatan sehari-hari untuk mencapai derajat kesehatan yang optimal.

Berdasarkan hasil penelitian oleh Utama (2014) bahwa ada peningkatan pengetahuan remaja putri tentang cara mengatasi keputihan merupakan dampak pendidikan kesehatan yang diberikan peneliti. Pendidikan kehatan merupakan upaya untuk meningkatkan kemampuan masyarakat melalui proses pembelajaran dari, oleh, untuk, dan bersama masyarakat, agar mereka dapat menolong dirinya sendiri, serta mengembangkan kegiatan yang bersumber daya masyarakat, sesuai dengan kondisi kebijakan publik yang berwawasan kesehatan. Hal ini didukung oleh minat remaja untuk ingin tahu tentang cara mengatasi keputihan.

Remaja yang memiliki pengetahuan yang baik tentang keputihan cenderung memiliki perilaku yang baik tentang pencegahan keputihan. Hal ini menunjukkan bahwa perilaku pada remaja dapat dimodifikasi melalui peningkatan pengetahuannya (Mokodongan et al, 2015).

3. Menganalisis Pengaruh Penyuluhan Kesehatan Reproduksi terhadap Pengetahuan Remaja Putri tentang Pencegahan Kejadian Leukorea Dari hasil analisis bivariat, menunjukkan bahwa nilai Pre Test 
Pengetahuan dan Post Test Pengetahuan mean 2216,000, nilai standar deviasi 43,818 dan nilai $p 0,000 \leq a 0.05$. Analisis menggunakan uji statistik Marginal Homogenity menunjukkan bahwa nilai $p$ $0,000 \leq a 0.05$, maka Ha diterima, yang berarti penyuluhan kesehatan reproduksi mempengaruhi pengetahuan remaja tentang Pencegahan Kejadian Leukorea di SMK Negeri 3 Banjarmasin.

Hal ini dapat dilihat dari peningkatan pengetahuan remaja sebelum dan sesudah dilakukan penyuluhan yang meningkat. Pengetahuan sebelum dilakukan responden yang didapat yaitu 1 orang $(3,3 \%)$ responden menunjukkan pengetahuan kurang, 13 orang $(43,3 \%)$ dan sesudah dilakukan penyuluhan terdapat pengaruh yang signifikan yaitu terdapat 30 orang $(100 \%)$ responden menunjukkan pengetahuan baik.

Menurut Lestari (2014), Faktor yang mempengaruhi pengetahuan adalah sebagai berikut yaitu: tingkat pendidikan, informasi yang didapat, pengalaman, budaya dan social ekonomi. Hal ini sejalan dengan penelitian Soetjiningsih (2014) yang menyatakan bahwa pada tahap usia remaja tengah, remaja sangat membutuhkan kawan-kawan. Selain itu, ia berada dalam masa kebingungan karena ia tidak tau harus memilih yang mana peka atau tida perduli, ramai-ramai atau sendiri, optimis atau pesimis. Oleh karena itu penyuluhan kesehatan reproduksi sangat diperlukan oleh remaja. Karena remaja adalah masa transisi/peralihan dari masa anak-anak ke masa dewasa.

Hal ini sejalan dengan penelitian Utama (2014) bahwa ada peningkatan pengetahuan remaja putri tentang cara mengatasi keputihan merupakan dampak pendidikan kesehatan yang diberikan peneliti. Pendidikan kesehatan merupakan upaya untuk meningkatkan kemampuan masyarakat melalui proses pembelajaran dari, oleh, untuk, dan bersama masyarakat, agar mereka dapat menolong dirinya sendiri, serta mengembangkan kegiatan yang bersumber daya masyarakat, sesuai 
dengan kondisi kebijakan publik yang

berwawasan kesehatan. Hal ini didukung

oleh minat remaja untuk ingin tahu tentang

cara mengatasi keputihan.

\section{Simpulan}

Dari hasil penelitian ini, upaya pemberian informasi mengenai pencegahan kejadian Leukorea perlu dilakukan secara komprehensif yang salah satunya melalui pembentukan pusat informasi dan konseling bagi remaja di sekolah yang para konselornya adalah dari para remaja yang diikutkan pelatihan dan telah mendapat pengetahuan tentang Leukorea dan juga pihak sekolah bisa menjalin kerjasama dengan pihak tenaga kesehatan sahingga responden dapat lebih mengantisipasi dirinya terhadap perilaku yang berisiko baik dengan cara pemberian penyuluhan ataupun seminar tentang kesehatan reproduksi dari sumber yang benar.

\section{Daftar Pustaka}

Aryani, Ratna. 2010. Kesehatan Reproduksi Problem dan Solusinya. Jakarta: Salemba Medika.

BKKBN. 2012. Survei Demografi dan Kesehatan Indonesia 2012 Kesehatan Reproduksi Remaja Laporan Pendahuluan. [Internet]. Tersedia dalam : http://www.bkkbn.go.id [diakses 27 September 2017].

Hutabarat H. 2007. Radang dan Beberapa Penyakit Lain pada Alat-Alat Genital Wanita, Dalam: Ilmu Kandungan, Edisi ke-2, Cetakan ke-3, Jakarta: Yayasan Bina Pustaka Sarwono Prawirodihardjo.

Lestary H, Sugiharti. 2007. Perilaku berisiko remaja di Indonesia menurut survey kesehatan reproduksi remaja Indonesia (SKRRI).

Manuaba, I.B.G., 2009. Memahami Kesehatan Reproduksi Wanita. Jakarta: EGC.

Mokodongan, Menthari H, Wantania, John dan Wagey, Freddy. 2015. Hubungan Tingkat Pengetahuan tentang Keputihan dengan Perilaku Pencegahan Keputihan pada Remaja Putri. Manado: Jurnal eClinic (eCI), Volume 3, Nomor 1.

Muninjaya, Gde AA. 2011. Manajemen Mutu Pelayanan Kesehatan. Jakarta: EGC.

Notoatmojo, S., 2012. Promosi Kesehatan dan Perilaku Kesehatan. Jakarta: Rineka Cipta.

Nugroho, Taufan., dan Indra Utama, Bobby. 2012. Masalah Kesehatan Reproduksi Wanita. Yogyakarta: Nuha Medika.

Nurul, Siti Qomariyah dkk. 2011. Infeksi Saluran Reproduksi (ISR) pada Perempuan Indonesia. Depok: Pusat Komunikasi Kesehatan Perspektif 
Gender bekerjasama dengan Ford Foundation.

Octaviana. 2012. Fakta Tentang Keputihan. [Internet]. Tersedia dalam : http://www.wikipedia.com [Diakses pada 26 Januari 2018].

Putu. 2009. Prevalensi Kejadian Keputihan. [Internet] Tersedia dalam : http://www.ziddu.com/download/50280 81/atPrevalensi-kejadian.keputihan.zip [diakses pada 26 Januari 2018].

Soetjiningsih. 2014. Perkembangan Anak dan Permasalahannya dalam Buku Ajar I Ilmu Perkembangan Anak Dan Remaja. Jakarta: Sagungseto.

Utama, Yofa Anggriani. 2014. Pengaruh Pendidikan Kesehatan dengan Media Booklet terhadap Tingkat Pengetahuan Remaja Putri dalam Mengatasi Keputihan di SMAN 1 Pagalaram Tahun 2014. [KTI] Palembang: AKBID Tunas Harapan Bangsa. 